\title{
Is family history an independent risk factor for stroke?
}

Motoo Kubota, Akira Yamaura, Jun-ichi Ono, Toru Itani, Norihide Tachi, Kazuo Ueda, Izumi Nagata, Shinji Sugimoto

Department of Neurosurgery, Chiba University School of Medicine, Japan M Kubota

A Yamaura

J Ono

Department of

Hygiene and

Occupational Health,

Nagoya City University

Medical School, Japan

T Itani

N Tachi

Second Department of Internal Medicine,

Kyushu University School of Medical

Science, Japan

K Ueda

Department of Neurosurgery, Kyoto University School of

Medicine, Japan

I Nagata

Department of Neurosurgery, Bibai

Rousai Hospital, Japan $S$ Sugimoto

Correspondence to:

Dr M Kubota, Department

of Neurosurgery, Chiba

of Neurosurgery, Chib

Medicine, Inohana 1-8-1

Chuou-ku, Chiba-shi, Chiba, 260 Japan.

Received 15 December 1996 and in final revised form

27 August 1996

Accepted 5 September 1996

\begin{abstract}
Objective-To estimate the influence of family history on the occurrence of stroke.

Methods-A case-control study was carried out from August 1992 to January 1994. The study population comprised 502 patients with a first stroke, aged between 20 and 70 years, who were treated at 48 affiliated hospitals. The same number of age and sex matched controls were selected from outpatients. Diagnoses were based on CT findings and clinical signs. There were 155 case-control pairs for subarachnoid haemorrhage, 158 for intracerebral haematoma, and 159 for cerebral infarction. Information about the patients and their families was obtained from a questionnaire which included the family histories of each subtype of stroke and other potential risk factors for stroke. The data were analysed focusing on the role of the family histories in the occurrence of stroke.
\end{abstract}

Results-In univariate analysis, the family histories of subarachnoid haemorrhage and intracerebral haematoma were positively associated with each of the subtypes of stroke (odds ratios $11 \cdot 24$ for subarachnoid haemorrhage, 2.39 for intracerebral haematoma), whereas family history of cerebral infarction was not a significant risk factor for its occurrence (odds ratio 1.41). Family history of intracerebral haematoma was correlated with a personal history of hypertension and habitual alcohol consumption. After adjustment for potential risk factors (hypertension, diabetes, hyperlipidaemia, obesity, alcohol consumption, and regular smoking), family history of subarachnoid haemorrhage still remained the most powerful risk factor for subarachnoid haemorrhage, whereas family history of intracerebral haematoma no longer showed a significant association with haematoma.

Conclusion-Genetic factors play a major part in the pathogenesis of subarachnoid haemorrhage, and family history of subarachnoid haemorrhage is the strongest independent risk factor for the disease. On the other hand, family history of intracerebral haematoma was not an independent risk factor for haematoma, but it might be a good predictor, which indirectly influences the pathogenesis of intracerebral haematoma via certain hereditary components such as hypertension, and even lifestyle factors such as alcohol consumption. In cerebral infarction, genetic factors play a minor part in its pathogenesis.

$(\mathcal{F}$ Neurol Neurosurg Psychiatry 1997;62:66-70)

Keywords: stroke; case-control study; family history; genetic factors

Stroke remains the third most common health problem among adults in Japan. Systemic hypertension is the strongest risk factor for stroke in the general population..$^{1-3}$ Diabetes, ${ }^{4-6}$ lipid abnormalities, ${ }^{78}$ ischaemic heart disease and atrial fibrillation, ${ }^{710}$ obesity, ${ }^{111}$ smoking, ${ }^{12-14}$ and alcohol consumption ${ }^{15-17}$ are other well documented risk factors. The role of genetic factors in the pathogenesis of stroke remains controversial. ${ }^{18}$ Some authors have reported the importance of genetic factors in stroke, ${ }^{18-22}$ whereas other studies have failed to show a genetic contribution. ${ }^{9102324}$ The World Health Organisation Task Force on Stroke and Other Cerebrovascular Disorders ${ }^{25}$ concluded that genetic or familial factors have not yet been shown to be important risk factors for stroke. Although the pathogenesis of subarachnoid haemorrhage, intracerebral haemorrhage, and cerebral infarction differ from each other, most of these studies did not classify stroke into clinical subtypes. This may explain the controversy. ${ }^{18} 26$

To evaluate the risk factors for each subtype of stroke, a case-control study was conducted. This report focuses on the role of family history in stroke.

\section{Subjects and methods}

We selected five university hospitals and 43 major general hospitals situated in large cities in Japan. This case-control study was based on 502 consecutive patients aged 20 to 70 with first episode of stroke. They were treated at the selected 48 neurological or neurosurgical institutes between 1 August 1992 and 31 January 1994.

A stroke is defined here as rapidly developed focal or global impairment of cerebral function, lasting more than 24 hours or leading to death, with no apparent cause other than vascular origin. Subtypes of stroke were confirmed by neurosurgeons or neurologists 
based on both the clinical picture and CT. Patients with recurrent episodes were excluded. Those with transient ischaemic attack without any evidence of cerebral infarction or with only evidence of old infarction but not in the clinically appropriate area on CT were also excluded.

For each case, age (within 5 years) and sex matched controls from outpatients who visited the same hospital at the earliest time after the patient's admission. Patients with a history of stroke were not selected as controls. Controls mostly had illnesses that were not serious or mild head injury.

The final 502 case-control pairs were analysed. There were 155 pairs for subarachnoid haemorrhage (SAH; 75 men and 80 women), 158 for intracerebral hemorrhage (ICH; 101 men and 57 women), and 189 for cerebral infarction (143 men and 46 women).

Information about the patients and their families was obtained from questionnaires in a standardised manner as soon after the event as possible. If the patients could not answer due to neurological deficits or other reasons, the same questionnaire was administered to close relatives. Information about the controls was also obtained from the same questionnaire in the same manner at the time of their first visit to the institute. The questionnaire included the following characteristics and experiences of the patients before their present illness: personal data (age, sex, and marital status); previous clinically diagnosed hypertension, diabetes mellitus, hyperlipidaemia, or any type of heart disease, and other personal medical history; and cigarette consumption, alcohol intake, working environment, and physical activity during leisure time. It also included the family histories of each stroke subtype among the first or second generation relatives (grandparents, parents, siblings, and children). The family history of stroke was elicited by the question: "Has anyone among your first or second generation relatives been diagnosed as having had subarachnoid haemorrhage/intracerebral haematoma/cerebral infarction?" All those who answered "yes" were classified as having a positive family history.

STATISTICAL ANALYSIS

All statistical analyses were carried out using the SPSS statistical package (SPSS $6 \cdot 1$ for the Macintosh, SPSS Japan Inc). Missing values were treated as system missing numbers. A $\chi^{2}$ test was used in univariate analysis. The odds ratios for each subtype of stroke were calcu-

Table 1 Number of pairs and age distribution

\begin{tabular}{llll}
\hline & $S A H$ & ICH & Infarction \\
\hline $\begin{array}{l}\text { Number of pairs: } \\
\text { men/women }\end{array}$ & $75 / 80$ & $101 / 57$ & $143 / 46$ \\
$\begin{array}{l}\text { Total } \\
\text { Age distribution: }\end{array}$ & 155 & 158 & 189 \\
$20-49$ & 61 & 37 & 25 \\
$50-59$ & 48 & 60 & 67 \\
60-70 & 46 & 61 & 97 \\
Mean age (SD): & $51.6(10 \cdot 6)$ & $54.3(9 \cdot 6)$ & $58.0(8.9)$ \\
Case & $51.6(10 \cdot 6)$ & $53.9(10 \cdot 2)$ & $57.8(9 \cdot 1)$ \\
\hline Control & & & \\
\hline
\end{tabular}

SAH = Subarachnoid haemorrhage; $\mathrm{ICH}=$ intracerebral haemorrhage; infarction = cerebral infarction. lated. The logistic regression technique was used for multivariate analysis using six (for subarachnoid haemorrhage and intracerebral haematoma) or seven (for cerebral infarction) variables comprising family history, systemic hypertension, diabetes mellitus, hyperlipidaemia, valvar disease (only for cerebral infarction), habitual alcohol consumption, and smoking. All statistical tests were two tailed. $P$ values $<0.05$ were regarded as indicating significance.

\section{Results}

Table 1 shows the number of case-control pairs for each subtype of stroke and age distribution. The mean age of the patients with subarachnoid haemorrhage was 51.6 (SD10.6) years, and those with intracerebral haematoma and cerebral infarction were 54.1 (SD 9.9) years, and 57.9 (SD 9.0) years respectively. Because age and sex were adjusted in this study, the age and sex distributions of the controls were the same as those of the cases.

Table 2 shows the number of patients and controls with potential risk factors for stroke. Family history of subarachnoid haemorrhage $(P=0.000)$, hypertension $(P=0.000)$, habitual alcohol consumption $(P=0.017)$, and smoking habit $(P=0.001)$ were significant risk factors for subarachnoid haemorrhage. Family histories of intracerebral haematoma $(P=0.002)$, hypertension ( $P=$ $0.000)$, and alcohol $(P=0.000)$ were also significant risk factors for intracerebral haematoma. Hypertension $(P=0.000)$, diabetes $(P=0.000)$, valvar disease $(P=$ $0.006)$, and smoking $(P=0.003)$ were risk factors for infarction.

Table 2 shows the odds ratios of the potential risk factors for stroke including family history. In univariate analysis, hypertension was a common powerful risk factor for all subtypes of stroke. The odds ratios (ORs) for subarachnoid haemorrhage, intracerebral haematoma, and cerebral infarction were 2.99 (95\% confidence interval (95\% CI) 1.77-5.03; $\mathrm{P}=0.000), 6 \cdot 14(95 \%$ CI 3.75-10.06; $\mathrm{P}=$ $0.000)$, and $3.72(95 \%$ CI $2 \cdot 41-5 \cdot 75 ; \mathrm{P}=$ $0.000)$ respectively. Diabetes was found to have a significant association only with cerebral infarction (OR $3 \cdot 26 ; 95 \%$ CI $1 \cdot 75-6 \cdot 20$; $P=0.000$ ). No significant relation was found between hyperlipidaemia and each subtype of stroke. For histories of heart condition, angina pectoris presented no significant positive relation to stroke, whereas valvar disease showed the strongest association with cerebral infarction (OR 10.40; 95\% CI 1.32-82.10; $P=0.006)$. Habitual alcohol consumption $(>250 \mathrm{~g} /$ week) significantly increased the risk of subarachnoid haemorrhage and intracerebral haematoma (OR $1.81,95 \%$ CI 1.11-2.95; $\quad P=0.017$ for subarachnoid haemorrhage, OR $2 \cdot 17,95 \%$ CI 1.36-3.47, $\mathrm{P}=0.001$ for intracerebral haematoma). Regular smokers ( $>1$ pack/day) had a notably higher risk of subarachnoid haemorrhage and cerebral infarction (OR $2 \cdot 15,95 \%$ CI $1.35-3.43, \quad P=0.001$ for subarachnoid 
Table 2 Number of patients and controls with risk factors and odds ratios

\begin{tabular}{|c|c|c|c|}
\hline & $S A H$ & $I C H$ & Infarction \\
\hline \multicolumn{4}{|l|}{ Family history: } \\
\hline$\%$ & $24 \cdot 5 / 2 \cdot 6$ & $38 \cdot 6 / 20 \cdot 9$ & $27 \cdot 0 / 20 \cdot 6$ \\
\hline $\begin{array}{l}\text { OR (95\% CI) } \\
\text { Hypertension: }\end{array}$ & $11 \cdot 24(3 \cdot 31-38 \cdot 22)^{\star \star}$ & Hypertension: & $1 \cdot 41(0 \cdot 83-2 \cdot 39)$ \\
\hline & $40 \cdot 6 / 18 \cdot 7$ & $69 \cdot 0 / 26 \cdot 6$ & $59 \cdot 3 / 28 \cdot 0$ \\
\hline \multicolumn{3}{|l|}{ Diabetes: } & $3.72(2 \cdot 41-5 \cdot 75)^{\star \star}$ \\
\hline$\%$ & $1 \cdot 9 / 3 \cdot 2$ & $11 \cdot 4 / 8 \cdot 2$ & $22 \cdot 8 / 8 \cdot 5$ \\
\hline $\begin{array}{c}\text { OR }(95 \% \text { CI }) \\
\text { Hyperlipidaemia: }\end{array}$ & \multicolumn{2}{|c|}{ Hyperlipidaemia: } & $3 \cdot 26(1 \cdot 75-6 \cdot 20)^{\star \star}$ \\
\hline$\%$ & $3 \cdot 9 / 5 \cdot 2$ & $8 \cdot 2 / 3 \cdot 8$ & $8 \cdot 5 / 11 \cdot 6$ \\
\hline $\begin{array}{l}\text { OR }(95 \% \mathrm{CI}) \\
\text { Valvar disease: }\end{array}$ & $0.75(0.25-2 \cdot 20)$ & $2 \cdot 18(0.80-5 \cdot 96)$ & $0.69(0.34-1.38)$ \\
\hline$\%$ & $0 / 0$ & $1 \cdot 9 / 0 \cdot 6$ & $5 \cdot 3 / 0 \cdot 5$ \\
\hline OR $(95 \%$ CI $)$ & - & $3 \cdot 12(0 \cdot 31-29 \cdot 35)$ & $10 \cdot 40(1 \cdot 37-82 \cdot 10)^{\star \star}$ \\
\hline \multicolumn{4}{|l|}{ Alcohol: } \\
\hline$\stackrel{\%}{\mathrm{OR}}(95 \% \mathrm{CD}$ & $38 \cdot 7 / 25 \cdot 8$ & $48 \cdot 1 / 30 \cdot 4$ & $40 \cdot 2 / 32 \cdot 3$ \\
\hline \multicolumn{4}{|l|}{ Smoking: } \\
\hline OR (95\% CI) & $\begin{array}{l}51 \cdot 6 / 32 \cdot 9 \\
2 \cdot 15(1 \cdot 35-3 \cdot 43)^{\star \star}\end{array}$ & $\begin{array}{l}38.6 / 20.9 \\
0.91(0.57-1.44)\end{array}$ & $\begin{array}{l}51.3 / 36.0 \\
1.86(1.23-2.84)^{\star \star}\end{array}$ \\
\hline
\end{tabular}

For abbreviations see table 1 .

$\%=$ Per cent of patients/controls with risk factor for stroke.

${ }^{\star} \mathrm{P}<0.05 ;{ }^{\star} \mathrm{P}<0.01$ by $\chi^{2}$ analysis.

haemorrhage, OR $1.8695 \%$ CI $1 \cdot 23-2 \cdot 84$, $P=0.003$ for cerebral infarction).

The role of family histories for each stroke subtype was also evaluated. Only four $(2 \cdot 6 \%)$ of 155 controls for subarachnoid haemorrhage had a family history of the disease compared with $37(24.5 \%)$ among the same number of patients with subarachnoid haemorrhage. In univariate analysis (table 2), the risk of subarachnoid haemorrhage was significantly higher in those who had a family history of the disease (OR 11.24; 95\% CI 3.31-38.22, $\mathrm{P}=$ $0 \cdot 000)$. Family history of intracerebral haematoma had a significant association with its occurrence (OR 2.39; 95\% CI 1.38-4.12, $P=0.003$ ), whereas family history of cerebral infarction was not positively associated with occurrence of infarction (OR $1.41 ; 95 \% \mathrm{CI}$ $0 \cdot 83-2 \cdot 39, P=0 \cdot 162$ ).

After adjustment for these potential risk factors (table 3), family history of subarachnoid haemorrhage remained a significant risk factor for subarachnoid haemorrhage (OR 15.88; $95 \%$ CI $1 \cdot 77-142 \cdot 11, P=0.011$ ), whereas family history of intracerebral haematoma showed no significant association with its occurrence (OR $1 \cdot 12 ; 95 \%$ CI $0.43-2 \cdot 90$, $\mathrm{P}=0.819$ ).

\section{Discussion}

The study shows that genetic factors play a major part in the pathogenesis of subarachnoid haemorrhage, and family history of subarachnoid haemorrhage is its strongest independent risk factor. On the other hand,

Table 3 Odds ratios for risk factors for stroke: multivariate analysis

\begin{tabular}{|c|c|c|c|}
\hline & $S A H$ & $\mathrm{ICH}$ & Infarction \\
\hline & OR $(95 \% C I)$ & OR $(95 \% C I)$ & OR $(95 \% C I)$ \\
\hline $\begin{array}{l}\text { Family history } \\
\text { Hypertension } \\
\text { Diabetes } \\
\text { Hyperlipidaemia } \\
\text { Alcohol } \\
\text { Smoking }\end{array}$ & $\begin{array}{c}15 \cdot 88(1 \cdot 77-142 \cdot 11)^{\star} \\
3.09(1 \cdot 23-7 \cdot 77)^{\star} \\
0.89(0 \cdot 19-9 \cdot 36) \\
0.34(0.05-2 \cdot 48) \\
2.04(0.86-4.86) \\
2.20(0.95-5 \cdot 14)\end{array}$ & $\begin{array}{l}1.12(0.43-2.90) \\
7.76(3.37-17.85)^{\star \star} \\
0.71(0 \cdot 17-2.88) \\
1.78(0.38-8.34) \\
2.63(1.14-6.02)^{\star} \\
0.86(0.37-1.98)\end{array}$ & $\begin{array}{l}0.82(0.39-1.74) \\
3.70(1.86-7.35)^{\star} \\
4 \cdot 15(1.47-11.74)^{\star \star} \\
0.42(0.16-1.07) \\
0.77(0.38-1.54) \\
1.72(0.39-1.74)\end{array}$ \\
\hline
\end{tabular}

For abbreviations see table 1

${ }^{\star} \mathbf{P}<0.05 ;{ }^{\star \star} \mathbf{P}<0.01$ by logistic regression. family history of intracerebral haematoma was not an independent risk factor.

One merit of the study is that the patients were diagnosed by neurologists or neurosurgeons based on CT findings as well as clinical condition. Some biases may exist ${ }^{27}$ because about half of our patients with stroke could not answer the questions due to their neurological deficits, and therefore one of their family members filled out the questionnaire. However, preliminary analysis between the data from the patients and those from family members showed no significant differences among the potential risk factors including family history.

Another potential source of bias is the reliability of incidence of positive family history. Some recall biases may exist, because we obtained the information on family history from the questionnaire. We classified all those who answered "yes" to the question: "Has anyone among your first or second generation relatives been diagnosed as subarachnoid haemorrhage/intracerebral haematoma/cerebral infarction?" as having a positive family history of each type of stroke. Patients and their family members had good recall about the health of their parents and siblings but not about their grandparents. In the pre-CT era, physicians made a diagnosis of stroke essentially based on clinical findings and it is reported that up to $24 \%$ of patients with intracerebral haematoma were diagnosed as having a cerebral infarction. ${ }^{3}$ The patients with intracerebral haematoma with ventricular perforation might have been diagnosed as subarachnoid haemorrhage due to blood in a spinal tap, which may explain the significant correlation of family history of subarachnoid haemorrhage with intracerebral haematoma as occurred in this study.

If genetic factors influence the aetiology of stroke, epidemiological studies might be expected to show a family history of stroke as an independent risk factor. ${ }^{26}$ Brass et $a l^{19}$ showed in a twin study on the aetiology of stroke that concordance rates for stroke were higher for monozygotic pairs $(17 \cdot 7 \%)$ than for dizygotic pairs $(3.6 \%)$, suggesting that there is a genetic contribution to prevalence of stroke. Although numerous studies have reported on this issue, most authors have failed to show family history as an independent risk factor for stroke. ${ }^{1} 102324$ The Royal College of Physicians does not list family history among the risk factors for stroke. ${ }^{28}$

In the present study, univariate analysis showed that both family history of subarachnoid haemorrhage and family history of intracerebral haematoma significantly raised the risk of each subtype of stroke, whereas no significant correlation was found between family history of cerebral infarction and occurrence of infarction. In multivariate analysis, after adjusting for other significant factors such as hypertension, diabetes, valvar disease, alcohol consumption, and smoking, family history of subarachnoid haemorrhage remained an independent risk factor for haemorrhage, whereas family history of intracerebral haematoma was 
no longer an independent risk factor for haematoma. Family history of intracerebral haematoma correlated significantly with hypertension and alcohol consumption.

There have been numerous reports that suggest a genetic component in the occurrence of cerebral aneurysms. It is well known that cerebral aneurysms more commonly occur in identical twins ${ }^{29}$ and family members of patients with subarachnoid haemorrhage..$^{21}$ 30-32 Norrgard $^{2}$ reported that at least $6.7 \%$ of the patients with aneurysms had blood relatives with the same disease. Although the exact percentage of patients with aneurysm that are familial is unclear, Toglia and $\mathrm{Samii}^{33}$ suggested that less than $2 \%$ of aneurysms occur in families.

Some differences in clinical features of ruptured aneurysms between familial and sporadic cases have been reported. ${ }^{21}$ For example, the mean age of familial patients is younger than that of sporadic patients. Aneurysms are often located at identical or mirror sites in family cases.

It has also been reported that cerebral aneurysms are associated with several other inherited disorders such as polycystic kidney, Ehlers-Danlos syndrome, and Marfan's syndrome..$^{203134}$ An autosomal dominant mode of inheritance has been suggested..$^{22}$ Several candidate genes for familial and sporadic intracranial aneurysms are currently being studied. It is postulated that patients with familial aneurysms might be carriers of a disorder of collagen metabolism. ${ }^{21} \mathrm{~A}$ specific deficiency of the arterial wall may be inherited in these familial cases. ${ }^{22}$

We showed that the relatives of patients with subarachnoid haemorrhage had more than a 10 -fold increased risk of subarachnoid haemorrhage compared with the controls. An angiographical investigation of asymptomatic relatives might be useful to reduce subarachnoid haemorrhage from ruptured aneurysms. ${ }^{30}$ Conventional angiography is still a gold standard to investigate cerebrovascular disease, but its invasiveness prevents its use in mass screening. Using magnetic resonance angiography, we have detected 47 unruptured aneurysms, which ranged from $2 \mathrm{~mm}$ to 27 $\mathrm{mm}$ in diameter, and have successfully treated them. We recommend this less invasive method for the screening of unruptured aneurysms.

Although several authors have reported familial occurrence of intracerebral haematoma, ${ }^{14}$ there are few reports concerning its family history. A recent study shows the importance of genetic factors as well as environmental factors in determining blood pressure, lipid concentrations, and body mass index. It has been suggested that hypertension is partly genetically determined and susceptibility to hypertension could mediate the possible familial factor increasing risk of stroke. ${ }^{35}$ Hyperlipidaemia $^{36}$ and diabetes ${ }^{4}$ are also known to show familial patterns of inheritance.

In the 1950 s the mortality from intracerebral haematoma for the Japanese was reported to be the highest among developed countries. Its incidence has sharply decreased ${ }^{37}$ mainly because of nutritional improvements and widely accepted antihypertensive treatment. ${ }^{2}$ The Honolulu heart study showed that the distribution of stroke types in those who migrated from Japan to Hawaii was similar to that of white people rather than native Japanese. ${ }^{38}$ These two studies showed that environmental factors were of primary importance in determining the occurrence of stroke.

Both genetic and environmental risk factors may have influence on the families of patients with intracerebral haematoma. ${ }^{39}$ Our study showed that family history of intracerebral haematoma is not an independent risk factor, but it seems to be a strong indicator for an increased risk of the disease. The study also suggested that family history of intracerebral haematoma influences its occurrence via both genetic (hypertension) and familial environmental components (hypertension and regular alcohol consumption) indirectly.

Cerebral infarction has also been seen to cluster in families, but few studies have quantified familial risks. ${ }^{40}$ Several haematological disorders such as antithrombin deficiencies, protein $C$ and protein $S$, polycythaemia vera, sickle cell anaemia, and essential thrombocythaemia are known risk factors for ischaemic stroke. $^{40}$ In the general population, these hereditary diseases play relatively minor parts in the pathogenesis of cerebral infarction, explaining about $1 \%$ of ischaemic stroke. ${ }^{41}$ Most hereditary disorders cause venous thrombosis rather than arterial thrombosis, and tend to be more frequent in younger generations. ${ }^{42}$ Animal studies suggested that genetic factors could play a part in the susceptibility to cerebral infarction during cerebral ischaemia. ${ }^{43}$

Because a family history of cerebral infarction was not an independent risk factor of ischaemic stroke in this study, the genetic factor seems to play a minor part in the pathogenesis of cerebral infarction. Further analyses in the subgroup of cerebral infarction, including cerebral thrombosis, cerebral embolism, and lacuna stroke, were attempted, but consistent results were not obtained due to the relatively small numbers.

This study was carried out as a part of a case-control study on risk factors of cerebrovascular disease supported by a grant from the Ministry of Labor. Forty eight institutes participated in the study, principally the Department of Neurosurgery,
Chiba University School of Medicine, Kyoto University School of Medicine, Bibai Rousai Hospital, Chiba Rousai Hospital, the Department of Hygiene and Occupational Health, Nagoya City University Medical School, the Second Department of Internal Medicine, Kyushu University School of Medical Technology, the Department of Hygiene and Public Health, Kagawa Medical College, the Department of Rehabilitation, National Circulatory Disease Center, and the Department of Mass Screening, Osaka Adult Disease Center. We acknowledge and thank the 73 doctors who participated in the study.

1 Folsom AR, Prineas RJ, Kaye SA, Munger RG. Incidence of hypertension and stroke in relation to body fat distribution and other risk factors in older women. Stroke 1990;21:701-6.

2 Omae T, Ueda K. Editorial review. Hypertension and cerebrovascular disease - the Japanese experience. Hypertension 1988;6:343-49

3 Phillips SJ, Whisnant JP. Hypertension and the brain. Arch Intern Med 1992;152:938-45.

4 Barnett AH, Eff C, Leslie RDG, Pyke DA. Diabetes in identical twins. a study of 200 pairs. Diabetologia 1981; 20:87-93. 
5 Lindegard B, Hillbom M. Associations between brain infarction, diabetes, and alcoholism: observations from the Gothenburg population cohort study. Acta Neurol Scand 1987;75:185-200.

6 Roehmbolt ME, Palumbo PJ, Whisnant JP. Transient ischemic attack and stroke in a community-based diabetic cohort. Mayo Clin Proc 1983;58:56-8.

7 Giroud M, Boutron MC, Gras P, et al. Plasma lipoproteins in cortical versus lacunar infarction with or without cardiactical versus lacunar infarction with or without carcontrol study. Neurol Res 1992,14:315-20.

8 Murai A, Tanaka T, Miyahara T, Kameyama M. Lipoprotein abnormalities in the pathogenesis of cerebral infarction and transient ischemic attack. Stroke 1981; 12:167-72.

9 Boysen G, Nyboe J, Appleyard M, et al. Stroke incidence and risk factors for stroke in Copenhagen, Denmark. Stroke 1988;19:1345-53.

10 Thompson SG, Greenberg G, Meade T. Risk factors for stroke and myocardial infarction in women in the United Kingdom as assessed in general practice: a case-control study. Br Heart $\mathcal{f} 1989 ; 61: 403-9$

11 Bouchard C, Tremblay A, Despres JP, et al. The response to long-term overfeeding in identical twins. N Engl $7 \mathrm{Med}$ 1990;322:1477-82

12 Higa $M$, Davanipour $Z$. Smoking and stroke. Neuroepidemiology 1991;10:211-22.

13 Love BB, Biller J, Jones MP, Adams HP, Bruno A. Cigarette smoking: a risk factor for cerebral infarction in young adults. Arch Neurol 1990;47:693-8.

14 Shinton R, Beevers G. Meta-analysis of relation between cigarette smoking and stroke. BMF 1989;298:789-94.

15 Camargo CA. Moderate alcohol consumption and stroke: The epidemiologic evidence. Stroke 1989;20:1611-26.

16 Gill JS, Shipley MJ, Tsementzis SA, Hornby RS, Gill S Hitchcock ER, Beevers G. Alcohol consumption-a risk factor for hemorrhagic and non-hemorrhagic stroke. Am f Med 1991;90:489-97.

17 Klatsky AL, Armstrong MA, Friedman GD. Alcohol use and subsequent cerebrovascular disease hospitalizations. Stroke 1989;20:741-6.

18 Graffagnino C, Gasecki AP, Doig GS, Hachinski VC. The importance of family history in cerebrovascular disease. Stroke 1994;25:1599-604.

19 Brass LM, Isaacsohn JL, Merikangas KR, Robinette CD. A study of twins and stroke. Stroke 1992;23:221-3.

20 Chauveau D, Pirson Y, Verellen-Dumoulin C, Macnicol A, Gonzalo A, Grunfeld JP. Intracranial aneurysms in autosomal dominant polycystic kidney disease. Kidney International 1994;45:1140-6.

21 Lozano AM, Lebranc R. Familial intracranial aneurysms. $f$ Neurosurg 1987;66:522-8.

22 Shinton R, Palsingh J, Williams B. Cerebral haemorrhage and berry aneurysm: evidence from a family for a pattern of autosomal dominant inheritance. $\mathcal{f}$ Neurol Neurosurg Psychiatry 1991;54:838-40.

23 Herman B, Schmitz PIM, Leyten ACM. Multivariate logistic analysis of risk factors for stroke in Tiburg, the
Netherlands. Am $\mathcal{F}$ Epidemiol 1983;118:514-25.

24 Whitfield JB, Martin NG. Plasma lipids in twins: environmental and genetic influence. Atherosclerosis 1983; 48:265-77.

25 WHO Task Force on Stroke and Other Cerebrovascular Disorders. Stroke 1989: Recommendations on stroke prevention, diagnosis, and therapy. Stroke 1989;20: 1407-31.

26 Alberts MJ. Genetic aspects of cerebrovascular Disease. Stroke 1990;25:25-30

27 Sackett DL. Bias in analytic reseach. 7 Chronic Dis 1979 ; 32:51-63.

28 Royal College of Physicians Working Party. Stroke-towards better management. London: Royal College of Physicians,

29 Schon F, Marshall J. Subarachnoid hemorrhage in identical twins. F Neurol Neurosurg Psychiatry 1984;47:81-3.

30 Evans TW, Venning MG, Strang FA, Donnai D. Dominant inheritance of intracranial aneurysm. $B M \mathfrak{J}$ 1981;283:824-5.

31 Fox JL, Ko JP. Familial intracranial aneurysms. Six cases among 13 siblings. F Neurosurg 1980;52:501-03.

32 Mellergard $\mathrm{P}$, Ljungoren $\mathrm{B}$, Brant L, Jonson U, Holtas S. HLA-typing in a family with six intracranial aneurysms. Br 7 Neurosurg 1989;3:479-86.

33 Toglia IU, Samii AR. Familial intracranial aneurysms. Dis Nerv Syst 1972;33:611-3.

34 Ruggieri PM, Poulos N, Masaryk T, et al. Occult intracranial aneurysms in polycystic kidney disease: screening with aneurysms in polycystic kianey disease: sci

35 Dyken MI, Wolf PA, Barnett HJM, et al. Risk factors in ischemic stroke: a statement for physicians by the Subcommitee on Risk Factors and the Stroke Council. Strok 1984;15:1105-11.

36 Hunt SC, Hasstedt SJ, Kuida H, Stults BM, Hopkins PN, Williams RR. Genetic heritability and common environmental components of resting and stressed blood pressure, lipids, and body mass index in Utah pedigree and twins. Am $\Im$ Epidemiol 1989;129:625-38.

37 Tanaka $\mathrm{H}$, Tanaka $\mathrm{Y}$, Hayashi $\mathrm{M}$, et al. Secular trends in mortality for cerebrovascular disease in Japan, 1960 to 1979. Stroke 1982;13:574-81.

38 Kagan A, Popper JOS, Rhoads GC. Factors related to stroke incidence in Hawaii Japanese men: the Honolulu heart study. Stroke 1980;11:14-21.

39 Marshall J. Familial incidence of cerebral hemorrhage. Stroke 1973;4:38 41

40 Brass LM, Shaker A Family history in patients with transient ischemic attacks. Stroke 1991;22:837-41.

41 Bogousslaysky J, Van Melle G, Regli F. The Lausanne Stroke Registry: analysis of 1000 consecutive patients Stroke Registry: analysis of 1000 conse

42 Hart RG, Kanter MC hematologic disorders and ischemi stroke: A selective review. Stroke 1990;21:1111-21.

43 Coyle O, Odenheimer DJ, Sing CF. Cerebral infarction after middle cerebral artery occlusion in progenies of spontaneously stroke-prone and normal rats. Stroke 1984;15:711-16. 